\title{
Lung volume reduction surgery: from National Emphysema Treatment Trial to non-intubated awake video-assisted thoracoscopic surgery
}

\author{
Volkan Kösek, Burkhard Thiel, Katina Nikolova, Eyad Al-Masri, Christian Begher, Christina Frank, \\ Bassam Redwan^ \\ Department of Thoracic Surgery, Klinikum Westfalen, Klinik am Park, Lünen, Germany \\ Contributions: (I) Conception and design: V Kösek, B Redwan; (II) Administrative support: B Thiel, K Nikolova, E Al-Masri, C Begher, B Redwan; \\ (III) Provision of study materials or patients: None; (IV) Collection and assembly of data: C Frank; (V) Data analysis and interpretation: None; (VI) \\ Manuscript writing: All authors; (VII) Final approval of manuscript: All authors. \\ Correspondence to: Bassam Redwan, MD. Department of Thoracic Surgery, Klinikum Westfalen, Klinik am Park, Brechtenerstrasse 59, 44536 Lünen, \\ Germany. Email: bassam.redwan@gmail.com.
}

\begin{abstract}
Chronic obstructive pulmonary disease (COPD) is a major public health problem. Loss of elastic recoil, hyperinflation and obstruction of the expiratory airflow lead to an increased breathing work, which results in dyspnea during minimal physical activity of the patients. Reduction of the lung volume in these patients leads to improvement of dyspnea, physical activity and quality of life in these patients. Beside endoscopic lung volume reduction (ELVR), lung volume reduction surgery (LVRS) represents an important and valuable treatment option for patients with advanced lung emphysema. Since the National Emphysema Treatment Trial (NETT), thoracic surgery experienced a remarkable evolution of the surgical techniques enabling safe surgery and quick recovery in this critically ill patient cohort. A paradigm shift from open surgical approaches to most minimally invasive techniques accompanied by improvement of anesthesiologic management of these patients was evident. Moreover, indications for LVRS, which were originally described in the NETT, were extended to apply for further groups of patients with advanced lung emphysema, enabling significant clinical improvement in well-selected patients with a low perioperative morbidity and mortality. The current review will give an overview of the historical approaches for LVRS, highlight the indications for LVRS and discuss the development of the surgical approaches.
\end{abstract}

Keywords: Lung volume reduction surgery (LVRS), lung emphysema, non-intubated video-assisted thoracoscopic surgery (VATS)

Submitted Sep 15, 2020. Accepted for publication Oct 14, 2020.

doi: 10.21037/atm-20-6430

View this article at: http://dx.doi.org/10.21037/atm-20-6430

\section{Introduction}

Chronic obstructive pulmonary disease (COPD) is a major public health problem. COPD, asthma and pneumonia are the third leading cause of death in the European Union (1) and the fourth common cause of death in North America with increasing prevalence and mortality rates (2). At least one third of the COPD cases is related to lung emphysema (3), which is characterized by permanent destructive enlargement of the distally located airspaces to the terminal bronchioles (4). Loss of elastic recoil, hyperinflation and obstruction of the expiratory airflow lead

^ ORCID: 0000-0002-0754-0603. 
to an increased breathing work, which results in dyspnea during minimal physical activity of the patients (1).

For patients with advanced lung emphysema, lung volume reduction surgery (LVRS) represents an important and valuable therapy option leading to improvement of survival and exercise capacity. The National Emphysema Treatment Trial (NETT) resembles one of the most important milestones of LVRS. Over the last few decades significant improvement of the surgical technique was achieved. The current review will give an overview of the historical approaches for LVRS, highlight the indications for LVRS and discuss the development of the surgical approaches.

\section{History of lung emphysema surgery}

Since 1920 several surgical approaches to improve dyspnea in patients with severe emphysema were reported (5). The operations included thoracoplasty, ostochondrectomy, stabilization of the membranous trachea, phrenicectomy, glomectomy and lung denervation (6).

Otto Charles Brantigan (1904-1981) may be considered the pioneer of LVRS (5). In the early 50s Brantigan and co-workers performed resections and plications via thoracotomy to remove the destroyed emphysematous lung tissue, suggesting that by reducing overall lung volume, elastic traction on the small airways may be restored and consequently expiratory airway obstruction could be reduced (1). Of 89 patients with severe bilateral diffuse and bullous lung emphysema, which were evaluated for surgery, LVRS was performed in 56 patients, of which 14 were operated on bilaterally $(7,8)$. A significant clinical improvement was observed in $75 \%$ of the patients (9). However, a high rate of early mortality (15-20\%) was reported $(5,10)$. The technique of Brantigan was discussed very critically at that time. Edward Arnold Gaensler (1921-2012) was one of the most renowned physicians in the field of pulmonary physiology at that time. $\mathrm{He}$ stated ironically: "it was difficult to believe that a disease characterized by diffuse loss of lung parenchyma could be effectively treated by resection of functioning lung" (5). Taking the high early mortality of the procedure together with the general scepsis towards this concept in account, no more intensive work in the field of LVRS was reported, until Joel David Cooper revived the concept of Brantigan and reported the results of bilateral pneumectomy (resection of breath or air $=$ volume reduction) in 20 patients with severe COPD (11). This can be considered the birth hour of the modern LVRS era.

It is important to distinguish between bullectomy and LVRS. Patients with giant bullae occupying more the one third of the hemithorax (vanishing lung syndrome) show a significant improvement of the lung function, when bullectomy is performed. By resecting these spaceoccupying large bullae, decompression of the adjacent lung tissue is achieved and consequently the lung function improves $(1,12)$. This concept was already well established long before Brantigan and Co-workers describe the concept of LVRS in patients with diffuse lung emphysema, which was later revived and refined by Cooper.

\section{Indications for LVRS}

The NETT may be considered as one of the most important milestones of modern LVRS (13). This prospective randomized, controlled, multicenter trial investigated long-term effects of LVRS compared to optimal medical therapy regarding survival, exercise capacity, quality of life, lung function and patient symptoms (14). Between January 1998 and July 2002, a total of 1218 patients were randomized either to LVRS or medical therapy and observed for a mean of 2.4 years $(13,15)$. In patients with upper lobe dominant emphysema and reduced baseline exercise capacity a significant improvement of survival, lung function, exercise capacity, dyspnea and quality of life was reported (13). During the trial, a subgroup defined by forced expiratory volume in 1 second (FEV1) less than or equal to $20 \%$ predicted and either a diffusing capacity for carbon monoxide (DLCO) less than or equal to $20 \%$ predicted or homogeneous emphysema demonstrated a 30-day mortality of $16 \%$ after LVRS compared to medical therapy $(\mathrm{P}=0.001)$ (16). The surviving patients in this group after LVRS showed no relevant clinical improvements in lung function, exercise capacity, or quality of life (14).

The NETT results led to more caution and some scepsis towards LVRS. Between 2003 and 2011, only 538 patients underwent LVRS according to the Society of Thoracic Surgeon's (STS) database (3). The indication for LVRS was limited to patients with upper lobe dominant heterogenous emphysema and several single center trials reported excellent results and long lasting improvement of lung function, quality of life and exercise capacity (17-21).

Experienced centers performing LVRS reported positive effects of the procedure in a wider spectrum of indications.

In NETT, 69 patients with the combination of FEV1 less than $20 \%$ predicted and either homogeneous emphysema 
or DLCO less than $20 \%$ predicted had a postoperative 30 -day mortality rate of $16 \%$ (13). Therefore, homogenous emphysema was considered a contraindication for LVRS.

However, in well-selected patients with homogenous emphysema, LVRS shows positive effects. Weder et al. reported long-lasting and significant improvement of lung function and reduction of dyspnea measured by the medical research council dyspnea score (MRCDS) in 138 patients with homogenous emphysema (22). The crucial criteria in selecting these patients for LVRS is severe hyperinflation with a residual volume to total lung capacity ratio (RV/TLC) greater than $60 \%$ and $\mathrm{FEV}-1 \%$ and DLCO $\%$ both above $20 \%$ predicted (23).

In patients with heterogenous emphysema and a severely impaired diffusion capacity (DLCO $<20 \%$ predicted), LVRS may be beneficial. By resecting the non-functioning lung tissue, gas exchange should not be impaired, but hyperinflation is reduced, and improvement of the lung function may occur. Beneficial effects of LVRS in patients with heterogenous emphysema and a DLCO $<20 \%$ predicted were already reported by Ciccone (21) and Caviezel (24). In both cohorts perioperative mortality was $0 \%$.

Repeated LVRS procedures in carefully selected patients may be safely performed with promising results. Kostron et al. reported 22 patients undergoing repeated LVRS. Significant improvement of FEV-1 and reduction of MRC-dyspnea score with a 90 -day mortality of $0 \%$ were observed (25).

Pulmonary hypertension represented an absolute contraindication for LVRS in the NETT and other trials (23). However, improvement of lung function, dyspnea and even pulmonary hemodynamics were reported, when non-perfused tissue is removed in patients with prominently heterogenous emphysema (26).

Patients with alpha-1-antitrypsin-deficiency (AATD) represent a special subgroup of emphysema. In the NETT, a total of 10 patients with AATD underwent LVRS (27). Although improvement of lung function and exercise capacity are achieved, durability of these beneficial effect is shorts in patients with AATD is shorter compared with patients without AATD after LVRS. Similar results were reported by the Zurich group (23) and are also discussed elsewhere in this issue.

\section{Evolution of the surgical approach for LVRS}

In the NETT, median sternotomy was performed in 406 of 580 patients (70\%) undergoing LVRS (14). Median sternotomy offers excellent exposure to both lungs especially to the anterior upper lobes without interfering with the chest wall muscles. Furthermore, no painful intercostal nerve damage is present, especially when chest tubes are placed under the rib cage. However, exposure to the lower lobes, especially on the left side, is impaired.

Muscle-sparing thoracotomy offers excellent exposure to the lower lobes and is performed by several surgeons in case of massive adhesions. However, this approach is not suitable for bilateral simultaneous procedures. Moreover, thoracotomy, even the muscle-sparing approach, still interferes with the chest wall muscle and should therefore not be considered for these critically ill patients.

With growing surgical experience in the minimally invasive field, more surgeons performed LVRS procedure by video-assisted thoracoscopic surgery (VATS). McKenna and co-workers reported comparable morbidity and functional results after LVRS by VATS compared to median sternotomy (28). VATS-LVRS allowed for earlier postoperative recovery at a lower cost than sternotomy.

Uniportal VATS (uVATS) represents the latest development of minimally invasive thoracic surgery and is gaining more popularity and acceptance over the last few years (29-31). Through a single-incision of $3-4 \mathrm{~cm}$, the whole thoracic cavity is reached and complex procedures, including vascular and bronchial sleeve resections may be performed. This approach is associated with even less postoperative pain than multiport VATS and allows for quick postoperative recovery.

In our institution, LVRS is performed by uniportal VATS. In patients with bilateral emphysema, a unilateral two-staged approach is favorized. Lately, we started to perform LVRS by uniportal subcostal VATS. Through a $4 \mathrm{~cm}$ incision placed below the rib cage, the hemithorax is accessed and LVRS may be safely performed (Figures 1-4). By avoiding the intercostal placement of the incision, less postoperative pain is observed, and patients show excellent and quick recovery from the procedure.

A further development of the minimally invasive approach is non-intubated awake VATS (NIVATS).

In 2006, Mineo and co-workers published their experience of awake non-resectional lung volume reduction under thoracic epidural anesthesia in 11 patients (32). By using a "no-knife" endostapler, emphysematous target zones are plicated. A faster recovery and satisfactory 6-month outcome compared to resectional LVRS was observed.

A few years later, Pompeo et al. conducted a prospective non-randomized study comparing results and costs of non- 

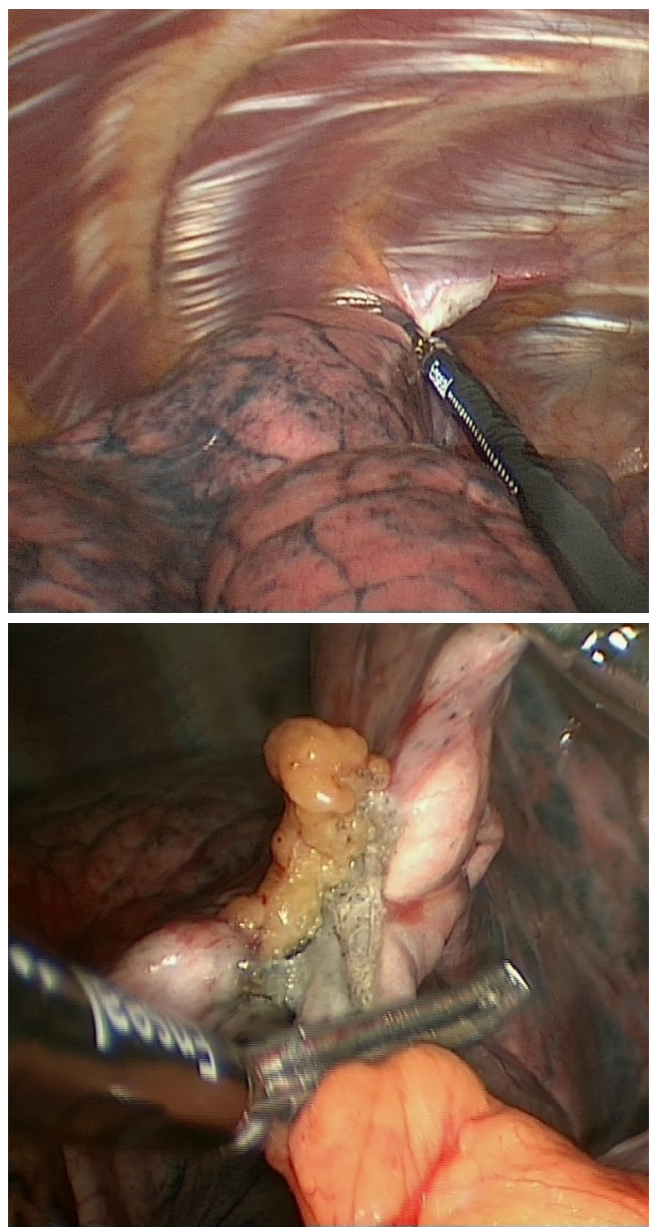

Figure 1 Pleurolysis during uniportal subcostal video-assisted thoracoscopic surgery (VATS) lung volume reduction surgery (LVRS).

resectional LVRS performed through awake or non-awake anesthesia (33). A total of 41 patients underwent awake non-resectional LVRS. The non-awake group comprised 19 patients. A better perioperative outcome, shorter hospital stays, and lower costs were reported in the awake group compared to the non-awake group. Thereby, comparable clinical outcomes were observed leading the authors to the conclusion that awake approach does not influence on late clinical benefit (33).

In a randomized controlled study conducted by the same group, awake resectional LVRS was compared to non-
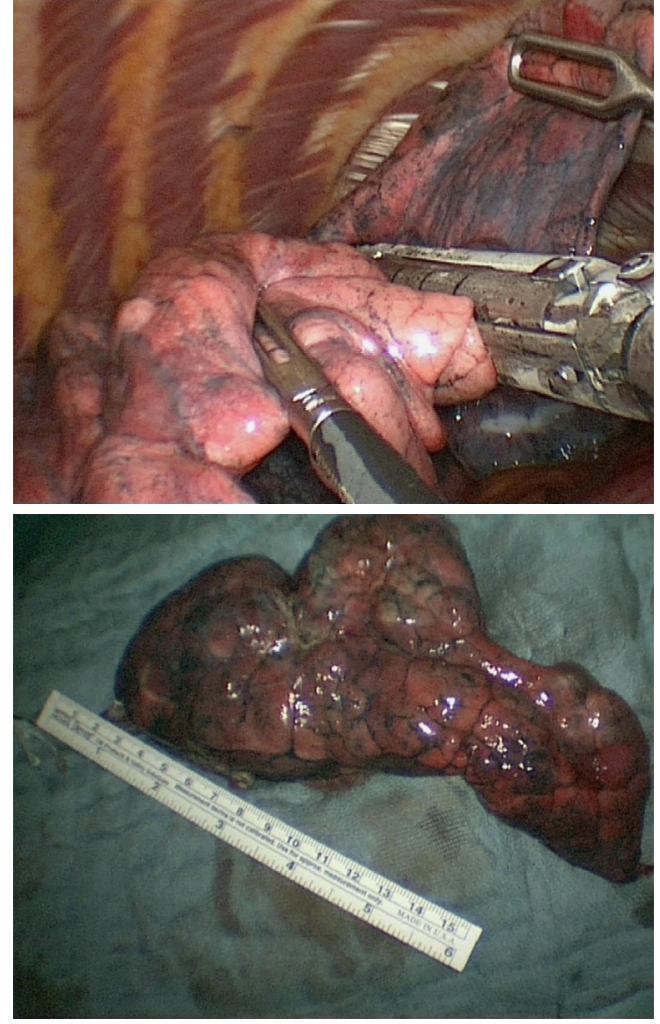

Figure 2 Resection of the emphysematous lung tissue from the right upper lobe.

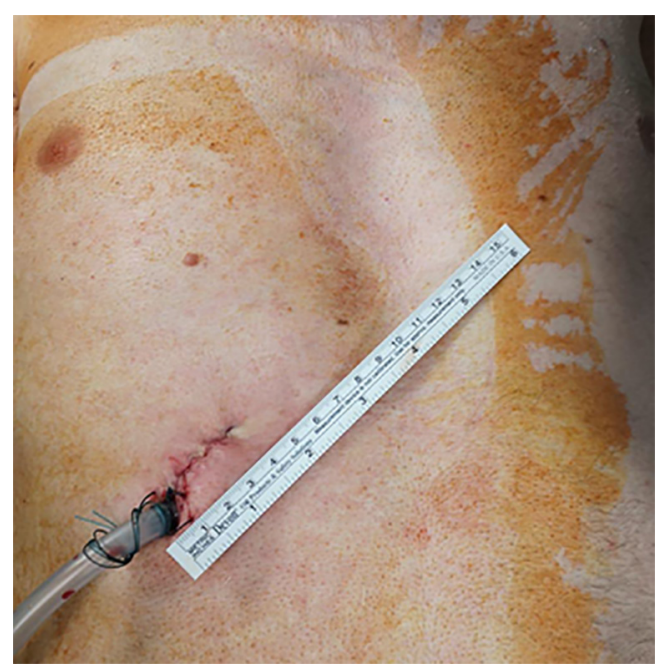

Figure 3 Subcostal incision with the chest tube inserted through the incision. 

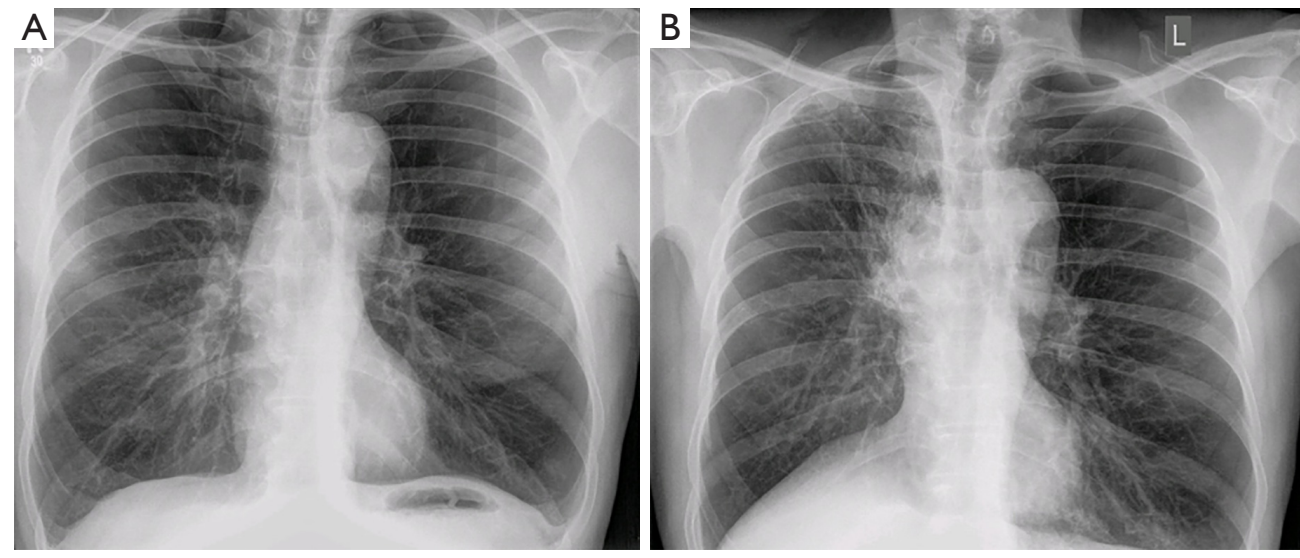

Figure 4 Pre- (left panel) and postoperative (right panel) X-ray following uniportal subcostal lung volume reduction surgery (LVRS) of the right upper lobe.

awake resectional LVRS (34). Despite the bias of comparing two different methods (resectional $v s$. non-resectional) in two different settings (awake vs. non-awake), the authors concluded that awake LVRS offers similar clinical benefit, thereby allowing a faster postoperative recovery (34).

\section{Conclusions}

LVRS is a safe and feasible treatment option in patients with lung emphysema. Careful patient selection is essential to achieve optimal clinical benefit even in patients beyond the classical LVRS indications as in the NETT.

Evolution of the surgical technique and the perioperative management including awake surgery allows for faster recovery of the patients without compromising the functional outcome.

\section{Acknowledgments}

Funding: None.

\section{Footnote}

Provenance and Peer Review: This article was commissioned by the editorial office, Annals of Translational Medicine for the series "Lung Emphysema". The article has undergone external peer review.

Conflicts of Interest: All authors have completed the ICMJE uniform disclosure form (available at http:// dx.doi.org/10.21037/atm-20-6430). The series "Lung Emphysema" was commissioned by the editorial office without any funding or sponsorship. BR served as the unpaid Guest Editor of the series and serves as an unpaid editorial board member of Annals of Translational Medicine from Oct 2019 to Sep 2021. The authors have no other conflicts of interest to declare.

Ethical Statement: The authors are accountable for all aspects of the work in ensuring that questions related to the accuracy or integrity of any part of the work are appropriately investigated and resolved.

Open Access Statement: This is an Open Access article distributed in accordance with the Creative Commons Attribution-NonCommercial-NoDerivs 4.0 International License (CC BY-NC-ND 4.0), which permits the noncommercial replication and distribution of the article with the strict proviso that no changes or edits are made and the original work is properly cited (including links to both the formal publication through the relevant DOI and the license). See: https://creativecommons.org/licenses/by-nc-nd/4.0/.

\section{References}

1. Russi EW, Stammberger U, Weder W. Lung volume reduction surgery for emphysema. Eur Respir J 1997;10:208-18.

2. Siafakas NM, Vermeire P, Pride NB, et al. Optimal assessment and management of chronic obstructive pulmonary disease (COPD). The European Respiratory Society Task Force. Eur Respir J 1995;8:1398-420.

3. Decker MR, Leverson GE, Jaoude WA, et al. Lung volume reduction surgery since the National Emphysema 
Treatment Trial: study of Society of Thoracic Surgeons Database. J Thorac Cardiovasc Surg 2014;148:2651-8.e1.

4. The definition of emphysema. Report of a National Heart, Lung, and Blood Institute, Division of Lung Diseases workshop. Am Rev Respir Dis 1985;132:182-5.

5. Naef AP. History of emphysema surgery. Ann Thorac Surg 1997;64:1506-8.

6. Deslauriers J. History of surgery for emphysema. Semin Thorac Cardiovasc Surg 1996;8:43-51.

7. Brantigan OC. The surgical treatment of pulmonary emphysema. WV Med J 1954;50:283-5.

8. Brantigan OC. Surgical treatment of pulmonary emphysema. Md State Med J 1957;6:409-14.

9. Brantigan OC, Mueller E. Surgical treatment of pulmonary emphysema. Am Surg 1957;23:789-804.

10. Brantigan OC, Mueller E, Kress MB. A surgical approach to pulmonary emphysema. Am Rev Respir Dis 1959;80:194-206.

11. Cooper JD, Trulock EP, Triantafillou AN, et al. Bilateral pneumectomy (volume reduction) for chronic obstructive pulmonary disease. J Thorac Cardiovasc Surg 1995;109:106-16; discussion 116-9.

12. Gaensler EA, Cugell DW, Knudson RJ, et al. Surgical management of emphysema. Clin Chest Med 1983;4:443-63.

13. Fishman A, Martinez F, Naunheim K, et al. A randomized trial comparing lung-volume-reduction surgery with medical therapy for severe emphysema. N Engl J Med 2003;348:2059-73.

14. Criner GJ, Cordova F, Sternberg AL, et al. The National Emphysema Treatment Trial (NETT) Part II: Lessons learned about lung volume reduction surgery. Am J Respir Crit Care Med 2011;184:881-93.

15. Rationale and design of The National Emphysema Treatment Trial: a prospective randomized trial of lung volume reduction surgery. The National Emphysema Treatment Trial Research Group. Chest 1999;116:1750-61.

16. National Emphysema Treatment Trial Research Group, Fishman A, Fessler H, et al. Patients at high risk of death after lung-volume-reduction surgery. N Engl J Med 2001;345:1075-83.

17. Brenner M, McKenna RJ, Jr., Chen JC, et al. Relationship between amount of lung resected and outcome after lung volume reduction surgery. Ann Thorac Surg 2000;69:388-93.

18. Flaherty KR, Kazerooni EA, Curtis JL, et al. Shortterm and long-term outcomes after bilateral lung volume reduction surgery: prediction by quantitative CT. Chest
2001;119:1337-46.

19. Tutic M, Lardinois D, Imfeld S, et al. Lung-volume reduction surgery as an alternative or bridging procedure to lung transplantation. Ann Thorac Surg 2006;82:208-13; discussion 213.

20. Ginsburg ME, Thomashow BM, Bulman WA, et al. The safety, efficacy, and durability of lung-volume reduction surgery: A 10-year experience. J Thorac Cardiovasc Surg 2016;151:717-24.e1.

21. Ciccone AM, Meyers BF, Guthrie TJ, et al. Longterm outcome of bilateral lung volume reduction in 250 consecutive patients with emphysema. J Thorac Cardiovasc Surg 2003;125:513-25.

22. Weder W, Tutic M, Bloch KE. Lung volume reduction surgery in nonheterogeneous emphysema. Thorac Surg Clin 2009;19:193-9.

23. Caviezel C, Schneiter D, Opitz I, et al. Lung volume reduction surgery beyond the NETT selection criteria. J Thorac Dis 2018;10:S2748-53.

24. Caviezel C, Schaffter N, Schneiter D, et al. Outcome After Lung Volume Reduction Surgery in Patients With Severely Impaired Diffusion Capacity. Ann Thorac Surg 2018;105:379-85.

25. Kostron A, Horn-Tutic M, Franzen D, et al. Repeated lung volume reduction surgery is successful in selected patients. Eur J Cardiothorac Surg 2015;48:710-5.

26. Caviezel C, Aruldas C, Franzen D, et al. Lung volume reduction surgery in selected patients with emphysema and pulmonary hypertension. Eur J Cardiothorac Surg 2018;54:565-71.

27. Stoller JK, Gildea TR, Ries AL, et al. Lung volume reduction surgery in patients with emphysema and alpha-1 antitrypsin deficiency. Ann Thorac Surg 2007;83:241-51.

28. McKenna RJ Jr, Benditt JO, DeCamp M, et al. Safety and efficacy of median sternotomy versus video-assisted thoracic surgery for lung volume reduction surgery. J Thorac Cardiovasc Surg 2004;127:1350-60.

29. Bertolaccini L, Batirel H, Brunelli A, et al. Uniportal video-assisted thoracic surgery lobectomy: a consensus report from the Uniportal VATS Interest Group (UVIG) of the European Society of Thoracic Surgeons (ESTS). Eur J Cardiothorac Surg 2019;56:224-9.

30. DE LA Torre M, González-Rivas D, Fernández R, et al. Uniportal VATS lobectomy. Minerva Chir 2016;71:46-60.

31. Bulgarelli Maqueda L, Garcia-Perez A, Minasyan A, et al. Uniportal VATS for non-small cell lung cancer. Gen Thorac Cardiovasc Surg 2020;68:707-15.

32. Mineo TC, Pompeo E, Mineo D, et al. Awake 
nonresectional lung volume reduction surgery. Ann Surg 2006;243:131-6.

33. Pompeo E, Tacconi F, Mineo TC. Comparative results of non-resectional lung volume reduction performed by awake or non-awake anesthesia. Eur J Cardiothorac Surg 2011;39:e51-8.

34. Pompeo E, Rogliani P, Tacconi F, et al. Randomized comparison of awake nonresectional versus nonawake resectional lung volume reduction surgery. J Thorac Cardiovasc Surg 2012;143:47-54.e1.

Cite this article as: Kösek V, Thiel B, Nikolova K, Al-Masri E, Begher C, Frank C, Redwan B. Lung volume reduction surgery: from National Emphysema Treatment Trial to non-intubated awake video-assisted thoracoscopic surgery. Ann Transl Med 2020;8(21):1468. doi: 10.21037/atm-20-6430 